\title{
Missing the Target?-Targeted Therapy in Small Cell Lung Cancer
}

\author{
Karin R. Purshouse \\ University of Edinburgh, Old College, Edinburgh, UK \\ Email: karinpurshouse@gmail.com
}

Received 26 May 2014; revised 28 June 2014; accepted 16 July 2014

Copyright (C 2014 by author and Scientific Research Publishing Inc.

This work is licensed under the Creative Commons Attribution International License (CC BY). http://creativecommons.org/licenses/by/4.0/

(c) (7) Open Access

\begin{abstract}
Small cell lung cancer [SCLC] is a devastating form of cancer, with most patients harbouring extensive disease at diagnosis and survival of less than $5 \%$ at five years. Progress in novel therapies has been limited. This specialist review explores current targeted therapy options and potential areas of development.
\end{abstract}

\section{Keywords}

Oncology, Small Cell Lung Cancer, Targeted Therapy, Drug Development

\section{Introduction}

Lung cancer causes 1.59 million deaths worldwide, accounting for nearly a fifth of all cancer deaths in the world. In 2012 alone, there were over 14 million new diagnoses of lung cancer globally [1]. Tobacco is the key causative agent, with rates of lung cancer continuing to increase in areas where smoking prevalence is rising, such as Asia and Africa [2] [3].

Commonly divided into small [SCLC] and non-small cell lung cancer [NSCLC], SCLC represents around $10 \%-15 \%$ of lung cancers [4]. Diagnosis is often late in the disease, when 5-year survival is less than 5\% [5]. The prevalence of SCLC is decreasing due to the global overall reduction in smoking, but estimates suggest that smoking prevalence will only decrease from $23.7 \%$ to $22 \%$ by 2030, leaving 872 million remaining smokers [6]. In the UK, despite a fall in smoking in the last five decades, $20 \%$ of the population continues to smoke [7]. Although the primary cause of SCLC is smoking, others include asbestos, silica and air pollution exposure.

SCLC arises from the kulchitsky cells of the APUD endocrine system. These are neuroendocrine cells of the bronchial tree. SCLC tumours demonstrate rapid growth and dissemination, with a cell doubling time of 25 217 days and early metastasis [8]. They classically grow as a large, bulky central mass with hilar and mediastinal lymphadenopathy, which can often be seen on a chest x-ray. They commonly metastasise to the liver, brain 
and bone, and are further characterised by paraneoplastic syndromes such as syndrome of inappropriate ADH secretion [SIADH] and ectopic adrenocorticotropic hormone [ACTH]. Suspicion is usually raised by a combination of symptoms [including cough, shortness of breath, haemoptysis] and chest x-ray findings as outlined above. A diagnosis is made by further imaging, usually computed tomography [CT], which can be extended to abdomen, pelvis and brain as part of staging, and tissue diagnosis, ideally by bronchoscopically obtained biopsy.

Staging is broadly limited [LD—within one hemithorax] or extensive disease [ED—beyond hemithorax], with around one-third diagnosed at the former and two-thirds at the latter stage. Very few patients present early enough for surgical resection. SCLC is acutely chemo-sensitive. LD patients are managed by chemotherapy [etoposide and cisplatin] and thoracic radiotherapy, and ED patients by chemotherapy [as above] alone. Prophylactic cranial radiation should be considered following initial treatment. Further chemotherapy [anthracyclines and topotecan are among those recommended] and palliative radiotherapy should be considered on recurrence. Treatment has stagnated in recent decades, and survival from diagnosis remains around 2 years for LD and less than a year for ED [9].

An explosion in understanding about carcinogenesis, summarised by the ten hallmarks of cancer (Figure 1), has seen the advent of targeted therapy in cancer care in the last two decades [10]. This has created a revolution not only in therapeutics, but also the methods of drug discovery, pharmaceutical economics and drug regulation. Epidermal growth factor receptor [EGFR] targeted therapy in the form of erlotinib and gefinitib is now recommended for use in NSCLC [11]. No targeted therapies are currently recommended for SCLC in the UK.

This specialist review explores the targeted therapies currently being investigated for SCLC. A summary of the pathways being targeted is shown in Figure 2, with a summary of targeted therapies shown in Table 1.

Table 1. Summary of targeted therapies, examples and current indications of potential success.

\begin{tabular}{|c|c|c|}
\hline Target & Example of drugs & Promising data? \\
\hline EGFR TK & Gefitinib Erlotinib & Yes, in patients with EGFR mutation. \\
\hline IGFR TK & AMG 479 BMS-754807 & None yet. Further trial results awaited. \\
\hline c-kit receptor TK & Imatinib & None yet. High study variability of c-kit mutation rate. \\
\hline c-MET receptor TK & AMG 102 & None yet. Trial results awaited. \\
\hline Farnesyltransferase & Tipifarnib & None yet. \\
\hline Src kinase & Dasatinib & None yet. \\
\hline mTOR & Everolimus Temsirolimus & Limited. Trial results awaited. \\
\hline PI3K & PF-4989216 & No trial data. \\
\hline PARP & Olaparib & Trial recently commenced. \\
\hline $\mathrm{Hh}$ & Vismodegib & No trial data. \\
\hline VEGF & $\begin{array}{l}\text { Bevacizumab Cediranib } \\
\text { Vandetanib Aflibercept }\end{array}$ & $\begin{array}{l}\text { Some potential in advanced disease with } \\
\text { bevacizumab. Aflibercept trial ongoing. }\end{array}$ \\
\hline MMPs & Marimastat Tanomastat & No benefit. \\
\hline Thalidomide & & $\begin{array}{l}\text { Therapeutic benefit in phase III trial but dose limited by } \\
\text { significant toxicity [thrombotic events]. }\end{array}$ \\
\hline PDGFR & Sorafenib Sunitinib & $\begin{array}{l}\text { Sorafenib_-none yet. Sunitinib-progression } \\
\text { free survival, other trials ongoing. }\end{array}$ \\
\hline Bcl-2 & AT-101 ABT-737 Obatoclax & None yet. \\
\hline Proteosome & Bortezomib & None yet \\
\hline PLK1 & Bi2536 & None yet \\
\hline HDAC & Vorinostat Belinostat & Yes in animal studies, no clinical trial data yet. \\
\hline Multi-drug resistance proteins & Biricodar & None yet \\
\hline HER2 & Trastuzumab & No trial data. \\
\hline CD56 & BB-10901 & Early phase studies promising \\
\hline GD3 & BEC2 & None yet. \\
\hline P53 & Vaccine & May indicate chemotherapy responsiveness, but unclear if causative. \\
\hline CTLA-4 & Ipilimumab & Trial awaited. \\
\hline
\end{tabular}




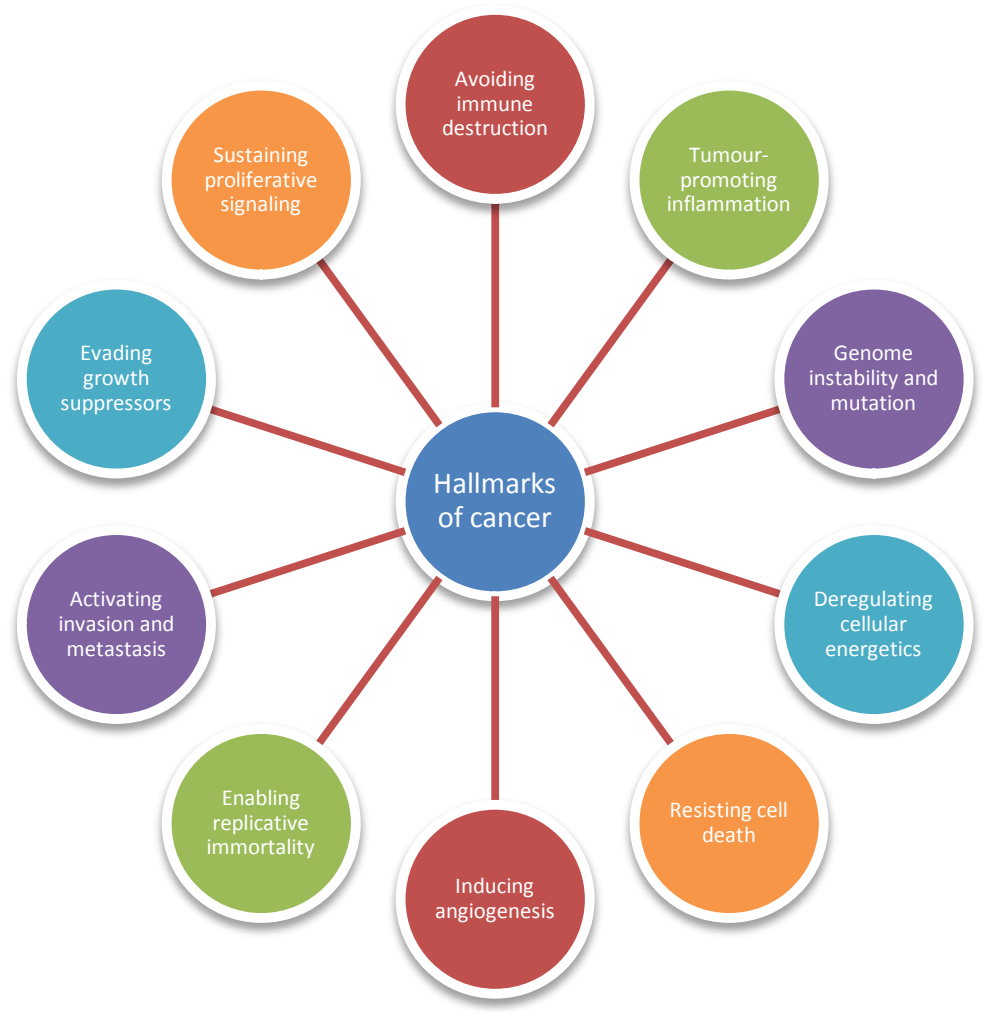

Figure 1. The ten hallmarks and characteristics of cancer. Adapted from Ref. [10].

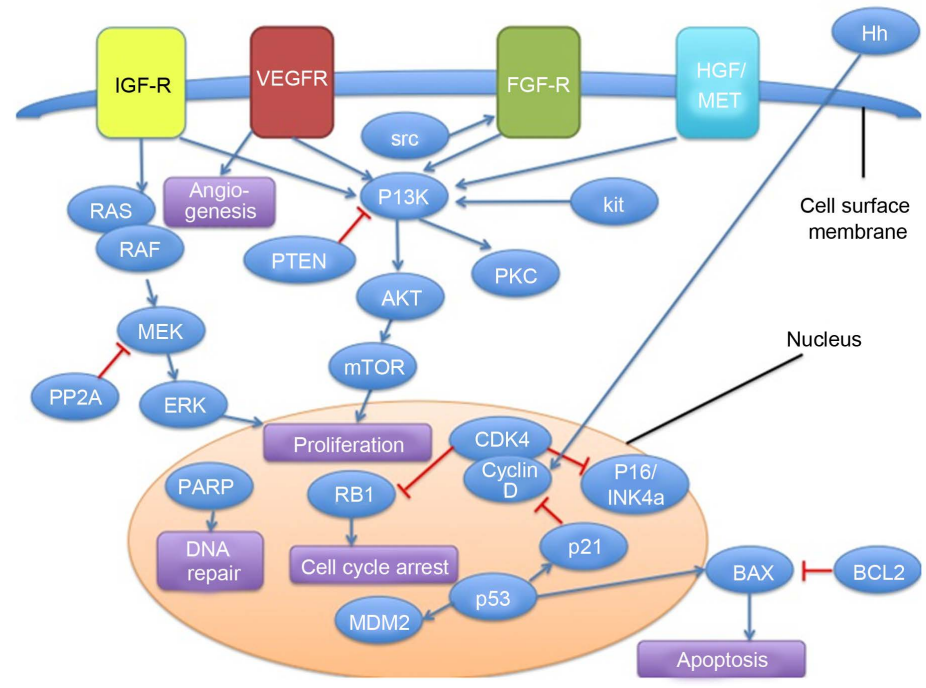

Figure 2. Abbreviated summary of key pathways for targeted therapies in SCLC. Adapted from Ref. [26] [p. 539] Abbreviations: BAX-BCL2-associated X protein Bcl2-B-cell lymphoma 2; CDK4 - cyclin dependent kinase 4, EGF-R-Endothelial growth factor receptor; ERK-extracellular signal regulated kinase; HGF/MET-Hepatic growth factor/MET]; Hh-Hedgehog; IGF-R-Insulin-like growth factor receptor 1; mTOR-mammalian target of rapamycin; MDM2-murine double minute 2; MEK-mitogen activated protein kinase; PI3K-Phosphoi-nositide 3-kinase; PTEN-phosphatase and tensin homolog; p16/INK4a — cyclin dependent kinase inhibitor p16; p21—cyclin dependent kinase inhibitor 1; PKC-protein kinase C; PP2A—protein phosphatase 2A RB1-retinoblastoma 1; RAS - rat sarcoma; VEGF-R-Vascular endothelial growth factor receptor. 


\section{Growth and Proliferation}

- EGFR-Tyrosine Kinase [TK] —Gefitinib and erlotinib are small molecule inhibitors [SMIs] of the EGFR-TK used in NSCLC; however SCLC harbours a lower incidence of EGFR mutations. Indicative of this, a 19-patient phase II study of gefitinib did not improve outcome of SCLC [12]. Case studies suggest patients harbouring a mutation may respond to EGFR inhibition, suggesting further studies are needed in this patient population [13] [14].

- Insulin-like growth factor receptor [IGFR] TK-Due to its important role in cell signalling and its interactions with EGFR, IGFR-TK inhibition has shown some promise in vitro, including increasing sensitivity to chemotherapy. [15] The results of a phase I/II trial with chemotherapy and IGFR-TK inhibitor AMG 479 or c-MET inhibitor AMG 102 are awaited [Clinical trial: 20060534].

- C-kit receptor TK-Imatinib, a drug more commonly known to target the bcr-abl fusion protein in chronic myeloid leukaemia, also targets c-kit, a protein over-expressed in 27.9\% - 83.3\% of ED SCLC [16] [17]. However, in phase II trials both selective and non-selective for patients harbouring c-kit overexpression, no benefit has been demonstrated in addition to chemotherapy [18] [19].

- C-MET receptor TK-c-MET mutations have been demonstrated in SCLC with positive in vitro c-MET inhibition studies. [20] In SCLC the only trial recently undertake is that outlined above, with results awaited.

- Farnesyltransferase-important for intracellular RAS signalling, farnesyltransferase inhibition by monotherapy tipifarnib in a phase II trial showed no benefit [21].

- Src kinase-Src has a role in Akt suppression, and may enhance chemotherapeutic efficacy [22]. A phase II trial of the multikinase [including src] inhibitor dasatinib had to be terminated early due to lack of efficacy [23].

- Mammalian target of rapamycin [mTOR] - Inhibition of this frequently activated pathway in single-agent studies with everolimus and temsirolimus showed limited efficacy but was well tolerated [24] [25]. Combination therapy studies are ongoing [26].

- Phosphoinositide 3-kinase [PI3K]-PI3K is commonly activated in SCLC either by a subunit catalytic mutation or loss of PTEN tumour suppressor gene. A pre-clinical study of PI3K inhibitor PF-4989216 showed some promise for patients harbouring PI3K mutations [27].

- Poly-ADP ribose polymerase inhibitors [PARPi]—PARP is an enzyme needed for DNA repair and olaparib inhibits this process, leading to cell death. A clinical trial has recently commenced for relapsed SCLC with olaparib [Clinical trial: LU2006].

- Hedgehog $[\mathrm{Hh}]-\mathrm{Hh}$ is involved in a range of pathways promoting cell propagation, in part through activation of the wnt/beta-catenin pathway. Vismodegib is among the most promising, although a phase I trial demonstrated limited anti-tumour activity in SCLC [28].

\subsection{Angiogenesis}

A more vascular cancer than NSCLC, SCLC harbours more vascular endothelial growth factor [VEGF] receptors and VEGF [26].

- Vascular Endothelial Growth Factor (VEGF) -

o Bevacizumab is a recombinant humanised monoclonal antibody against the VEGF-A receptor, and has been investigated in a number of phase II trials. Single-arm trials for LD and ED SCLC have shown some promising results in both maintenance studies and in combination with chemotherapy [29] [30]. However, a randomised phase II trial of fifty-two patients showed improved progression free survival, but not overall survival [31]. Other studies suggest this could be useful in advanced, chemoresistant patients in a second-line treatment study [32].

o Other VEGF inhibitors: SMIs Cediranib and Vandetanib have both reached phase II trials in recurrent disease and post-chemotherapy respectively, neither of which demonstrated survival benefit [33] [34]. Aflibercept is a novel fusion protein that binds, and thus blocks, VEGFA/B. A phase II trial with Topotecan is ongoing [Clinical trial: NCT00828139].

- Matrix metalloproteinases [MMPs] — these enzymes are involved in extracellular matrix remodelling, tumour growth and metastasis. [26] The last trials were over a decade ago, with no survival benefit [35] [36].

- Thalidomide-Despite an unknown mechanism, thalidomide reached phase III trials owing to its antiangiogenic effects. The Intergroup study demonstrated a survival benefit in patients with a better performance status, however all trials have shown significant rates of thrombotic events [37] [38]. Balancing adequate 
dosing with toxicity is a key limitation.

- Platelet-derived Growth Factor receptor [PDGFR]—multikinase inhibitors Sorafenib and Sunitinib inhibit VEGFR in addition to PDGFR, and also target raf kinase [sorafenib] and kit [sunitinib] amongst others. Sorafenib has shown significant toxicity and limited efficacy in Phase II trials with chemotherapy and as maintenance therapy [39]. Sunitinib recently demonstrated improved progression free survival versus placebo as maintenance therapy with a trend towards improved overall survival in a randomised phase II trial [40].

\subsection{Apoptosis}

- Bcl-2-Bcl-2 is found at higher concentrations in SCLC in its role as an apoptosis inhibitor. Bcl-2 inhibitors include an antisense Bcl-2 oligonucleotide and BH3-mimetics. [26] Of the latter, AT-101 has reached phase I/II clinical trial in relapsed SCLC patients. It did not show any treatment response, but BH3-mimetics remain the most promising anti-apopotic agents [41].

- Proteosome inhibitors - the 26S ubiquitin-proteosome complex promotes the Bcl-2 pathway. Bortezomib inhibits this complex, although a phase II monotherapy trial in relapsed SCLC patients did not improve outcomes [42].

- Polo-like kinase [PLK1]_PLK1 is involved with various stages of mitosis, and its inhibition induces cell cycle arrest and apoptosis. A monotherapy phase II trial of PLK1-inhibitor Bi2536 was ended early as there was a lack of efficacy [43]. The mechanism of Histone deacetylase inhibitors [HDACi] includes Plk1 inhibition (see Table 1) [44].

- HDAC-epigenetic modulation is among the most exciting targeting options. HDAC is required for acetylation of histones and other proteins, thereby affecting gene and protein expression. Animal studies suggest SCLC may be particularly sensitive to HDACi [45]. Numerous trials are ongoing, such as a trial of vorinostat with chemotherapy [Clinical trial: NCT00702962].

\subsection{Drug Resistance}

- Multidrug-resistance proteins: To address chemotherapy resistance, therapy targeting drug resistance mechanisms, including P-glycoprotein and multi-drug resistance-associated protein-1 [MDR-1], has been explored. A trial of biricodar with chemotherapy was terminated early due to lack of efficacy [Clinical trial: NCT00003847].

- Human epidermal growth factor receptor 2 [HER2]—Pre-clinical studies suggest HER2 is up regulated in chemoresistant SCLC and recent research suggests trastuzumab could inhibit this effect via antibody-dependent cell-mediated toxicity [46]. This is yet to reach in vivo studies.

\subsection{Immune System}

- CD56-a novel DM1-conjugated anti-CD56 antibody, BB-10901, targets this marker on SCLC cells. Early phase studies suggest some benefit in a second-line treatment setting, although formal results are awaited [47].

- CTLA-4-CTLA-4 on T-cells switches off the binding of T-cells to cancer cells. Ipilimumab binds and blocks CTLA-4, which maintains T-cell destruction of cancer. It is licensed in melanoma, but is currently in a multi-centre phase III trial in the USA for SCLC [Clinical trial: CA184-156].

- GD3-GD3 gangliosides are on most SCLC cells, and BEC2 is a GD3-mimicking, IgG2b monoclonal antibody. When used with bacille Calmette-Guerin [bCG], it triggers an immune response against GD3. A phase III trial in LD patients showed no benefit [47] [48].

- P53-a key gatekeeper in the cell cycle, p53 is often mutated in SCLC. This is exploited via a vaccine, which promotes an immune response against p53. A clinical trial showed a correlation between immunological activation and chemotherapy response [49]. Another vaccine under investigation is against alltrans retinoic acid [The ICE trial: Clinical trial: NCT00617409].

\section{Discussion}

Treatment options for SCLC have progressed little in the last few decades. Research is more heavily weighted 
towards NSCLC, and novel therapies have seen less success in SCLC. The majority of early phase clinical trials have been unsuccessful, mirroring a trend in cancer therapeutics that sees only $5 \%$ of drugs entering trial stage gaining approval and a 70\% attrition rate at Phase I trial [50]. Lack of efficacy and toxicity are the major causes of failure in cancer trials. Coupled with systemic inefficiency in drug discovery and design, the rocketing cost of drug discovery and rising patient expectations, the challenges faced by targeted in SCLC reflect challenges in other clinical fields.

Of the therapies outlined above, bevacizumab and potentially IGFR inhibitors may show greatest promise. Thalidomide dose is limited by toxicity despite evidence of clinical benefit, and some of the proliferation targeting therapies, such as EGFR and c-kit, and immunotherapies may prove successful in a selected patient population. Many of these drugs remain at the trial stage, making any conclusions difficult.

The search for surrogate treatment markers, such as biomarkers and other drug response indicators, may be a method of expediting targeted therapy trials to reduce the timescale and risk of harm to patients [51]. Computational drug design methods could also help to screen for potential drugs and design them to overcome toxicity and pharmacokinetic barriers, such as the recently described Boolean in-silico model [52].

\section{Conclusion}

There are no current targeted therapies licensed for use in SCLC. Of those under investigation, bevacizumab and IGFR inhibitors may offer the greatest potential, but many others are at a trial stage. Novel drug design methods may increase the efficiency of targeted drug design in SCLC.

\section{References}

[1] International Agency for Research on Cancer, World Health Organisation (2012) GLOBOCAN 2012-Estimated Cancer Incidence, Mortality and Prevalence Wordwide. http://globocan.iarc.fr/Pages/fact_sheets_cancer.aspx

[2] Ezzati, M., Henley, S.J., Lopez, A.D. and Thun, M.J. (2005) Role of Smoking in Global and Regional Cancer Epidemiology: Current Patterns and Data Needs. International Journal of Cancer, 116, 963-971. http://dx.doi.org/10.1002/ijc.21100

[3] Jemal, A., Bray, F., Center, M.M., Ferlay, J., Ward, E. and Forman, D. (2011) Global Cancer Statistics. CA: A Cancer Journal for Clinicians, 61, 69-90. http://dx.doi.org/10.3322/caac.20107

[4] Riaz, S.P., Lüchtenborg, M., Coupland, V.H., Spicer, J., Peake, M.D. and Møller, H. (2012) Trends in Incidence of Small Cell Lung Cancer and All Lung Cancer. Lung Cancer, 75, 280-284. http://dx.doi.org/10.1016/j.lungcan.2011.08.004

[5] Cancer Research UK (2012) Statistics and Outlook for Lung Cancer. http://www.cancerresearchuk.org/cancer-help/type/lung-cancer/treatment/statistics-and-outlook-for-lung-cancer

[6] Méndez, D., Alshanqeety, O. and Warner, K.E. (2013) The Potential Impact of Smoking Control Policies on Future Global Smoking Trends. Tobacco Control, 22, 46-51. http://dx.doi.org/10.1136/tobaccocontrol-2011-050147

[7] (2014) Ash: Ash. Action on Smoking and Health; Facts at a Glance. Smoking Statistics. http://www.ash.org.uk/files/documents/ASH_93.pdf

[8] Harris, K., Khachaturova, I., Azab, B., et al. (2012) Small Cell Lung Cancer Doubling Time and Its Effect on Clinical Presentation: A Concise Review. Clinical Medicine Insights: Oncology, 6, 199-203. http://dx.doi.org/10.4137/CMO.S9633

[9] Jackman, D.M. and Johnson, B.E. (2005) Small-Cell Lung Cancer. The Lancet, 366, 1385-1396. http://dx.doi.org/10.1016/S0140-6736(05)67569-1

[10] Hanahan, D. and Weinberg, R.A. (2011) Hallmarks of Cancer: The Next Generation. Cell, 144, 646-674. http://dx.doi.org/10.1016/j.cell.2011.02.013

[11] NICE Pathways (2012) Treatment for Non-Small Cell Lung Cancer. http://pathways.nice.org.uk/pathways/lung-cancer\#path=view\%3A/pathways/lung-cancer/treatment-for-non-small-celllung-cancer.xml\&content=view-node\%3Anodes-first-line-and-maintenance-chemotherapy-for-advanced-or-metastaticnon-small-cell-lung-cancer

[12] Moore, A.M., Einhorn, L.H., Estes, D., Govindan, R., Axelson, J., Vinson, J., Breen, T.E., Yu, M. and Hanna, N.H. (2006) Gefitinib in Patients with Chemo-Sensitive and Chemo-Refractory Relapsed Small Cell Cancers: A Hoosier Oncology Group Phase II Trial. Lung Cancer, 52, 93-97. http://dx.doi.org/10.1016/j.lungcan.2005.12.002

[13] Okamoto, I., Araki, J., Suto, R., Shimada, M., Nakagawa, K. and Fukuoka, M. (2006) EGFR Mutation in GefitinibResponsive Small-Cell Lung Cancer. Annals of Oncology, 17, 1028-1029. http://dx.doi.org/10.1093/annonc/mdj114 
[14] Zakowski, M.F., Ladanyi, M., Kris, M.G. and Memorial Sloan-Kettering Cancer Center Lung Cancer OncoGenome Group (2006) EGFR Mutations in Small-Cell Lung Cancers in Patients Who Have Never Smoked. New England Journal of Medicine, 355, 213-215. http://dx.doi.org/10.1056/NEJMc053610

[15] Warshamana-Greene, G.S., Litz, J., Buchdunger, E., García-Echeverría, C., Hofmann, F. and Krystal, G.W. (2005) The Insulin-Like Growth Factor-I Receptor Kinase Inhibitor, NVP-ADW742, Sensitizes Small Cell Lung Cancer Cell Lines to the Effects of Chemotherapy. Clinical Cancer Research, 11, 1563-1571. http://dx.doi.org/10.1158/1078-0432.CCR-04-1544

[16] Potti, A., Moazzam, N., Ramar, K., Hanekom, D.S., Kargas, S. and Koch, M. (2003) CD117 (c-KIT) Overexpression in Patients with Extensive-Stage Small-Cell Lung Carcinoma. Annals of Oncology, 14, 894-897. http://dx.doi.org/10.1093/annonc/mdg253

[17] Lu, H.Y., Zhang, G., Cheng, Q.Y., Chen, B., Cai, J.F., Wang, X.J., Zhang, Y.P., Wang, Z., Lu, Z.Y., Xie, F.J. and Mao, W.M. (2012) Expression and Mutation of the c-Kit Gene and Correlation with Prognosis of Small Cell Lung Cancer. Oncology Letters, 4, 89-93.

[18] Schneider, B.J., Kalemkerian, G.P., Ramnath, N., Kraut, M.J., Wozniak, A.J., Worden, F.P., Ruckdeschel, J.C., Zhang, X.H., Chen, W. and Gadgeel, S.M. (2010) Phase II Trial of Imatinib Maintenance Therapy after Irinotecan and Cisplatin in Patients with c-Kit-Positive, Extensive-Stage Small-Cell Lung Cancer. Clinical Lung Cancer, 11, 223-227. http://dx.doi.org/10.3816/CLC.2010.n.028

[19] Spigel, D.R., Hainsworth, J.D., Simons, L., Meng, C., Burris III, H.A., Yardley, D.A., Grapski, R., Schreeder, M., Mallidi, P.V. and Greco, F.A. (2007) Irinotecan, Carboplatin, and Imatinib in Untreated Extensive-Stage Small-Cell Lung Cancer: A Phase II Trial of the Minnie Pearl Cancer Research Network. Journal of Thoracic Oncology, 2, 854861. http://dx.doi.org/10.1097/JTO.0b013e31814617b7

[20] Maulik, G., Kijima, T., Ma, P.C., Ghosh, S.K., Lin, J., Shapiro, G.I., Schaefer, E., Tibaldi, E., Johnson, B.E. and Salgia, R. (2002) Modulation of the c-Met/Hepatocyte Growth Factor Pathway in Small Cell Lung Cancer. Clinical Cancer Research, 8, 620-627.

[21] Heymach, J.V., Johnson, D.H., Khuri, F.R., Safran, H., Schlabach, L.L., Yunus, F., DeVore III, R.F., De Porre, P.M., Richards, H.M., Jia, X., Zhang, S. and Johnson, B.E. (2004) Phase II Study of the Farnesyl Transferase Inhibitor R115777 in Patients with Sensitive Relapse Small-Cell Lung Cancer. Annals of Oncology, 15, 1187-1193. http://dx.doi.org/10.1093/annonc/mdh315

[22] Ueda, Y., Igishi, T., Hashimoto, K., Suyama, H., Araki, K., Sumikawa, T., Takeda, K., Nakazaki, H., Matsunami, K., Kodani, M., Shigeoka, Y., Matsumoto, S. and Shimizu, E. (2009) Synergistic Cell Growth Inhibition by the Combination of Amrubicin and Akt-Suppressing Tyrosine Kinase Inhibitors in Small Cell Lung Cancer Cells: Implication of cSrc and Its Inhibitor. International Journal of Oncology, 34, 689-696.

[23] Miller, A.A., Pang, H., Hodgson, L., Ramnath, N., Otterson, G.A., Kelley, M.J., Kratzke, R.A., Vokes, E.E. for the Cancer and Leukemia Group B (2010) A Phase II Study of Dasatinib in Patients with Chemosensitive Relapsed Small Cell Lung Cancer [Cancer and Leukemia Group B 30602]. Journal of Thoracic Oncology, 5, 380-384. http://dx.doi.org/10.1097/JTO.0b013e3181cee36e

[24] Pandya, K.J., Dahlberg, S., Hidalgo, M., Cohen, R.B., Lee, M.W., Schiller, J.H. and Johnson, D.H. (2007) A Randomized, Phase II Trial of Two Dose Levels of Temsirolimus [CCI-779] in Patients with Extensive-Stage Small-Cell Lung Cancer Who Have Responding or Stable Disease after Induction Chemotherapy: A Trial of the Eastern Cooperative Oncology Group [E1500]. Journal of Thoracic Oncology, 2, 1036-1041. http://dx.doi.org/10.1097/JTO.0b013e318155a439

[25] Tarhini, A., Kotsakis, A., Gooding, W., Shuai, Y., Petro, D., Friedland, D., Belani, C.P., Dacic, S. and Argiris, A. (2010) Phase II Study of Everolimus [RAD001] in Previously Treated Small Cell Lung Cancer. Clinical Cancer Research, 16, 5900-5907. http://dx.doi.org/10.1158/1078-0432.CCR-10-0802

[26] Zhang, Y. and He, J. (2013) The Development of Targeted Therapy in Small Cell Lung Cancer. Journal of Thoracic Disease, 5, 538-548.

[27] Walls, M., Baxi, S.M., Mehta, P.P., Liu, K.K.C., Zhu, J.J., Estrella, H., Li, C.Z., Zientek, M., Zong, Q., Smeal, T. and Yin, M.J. (2014) Targeting Small Cell Lung Cancer Harboring PIK3CA Mutation with a Selective Oral PI3K Inhibitor PF-4989216. Clinical Cancer Research, 20, 631-643. http://dx.doi.org/10.1158/1078-0432.CCR-13-1663

[28] LoRusso, P.M., Rudin, C.M., Reddy, J.C., Tibes, R., Weiss, G.J., Borad, M.J., et al. (2011) Phase I Trial of Hedgehog Pathway Inhibitor Vismodegib [GDC-0449] in Patients with Refractory, Locally Advanced or Metastatic Solid Tumors. Clinical Cancer Research, 17, 2502-2511. http://dx.doi.org/10.1158/1078-0432.CCR-10-2745

[29] Patton, J.F., Spigel, D.R., Greco, F.A., Liggett, W.H., Zubkus, J.D., Baskette, M., Schreeder, M., Woytowitz, D., Nelson, E. and Hainsworth, J.D. (2006) Irinotecan [I], Carboplatin [C], and Radiotherapy [Rt] Followed by Maintenance Bevacizumab [b] in the Treatment [tx] of Limited-Stage Small Cell Lung Cancer [LS-SCLC]: Update of a Phase II Trial of the Minnie Pearl Cancer Research Network. Journal of Clinical Oncology, 24, 7085. 
[30] Ready, N.E., Dudek, A.Z., Pang, H.H., Hodgson, L.D., Graziano, S.L., Green, M.R. and Vokes, E.E. (2011) Cisplatin, Irinotecan, and Bevacizumab for Untreated Extensive-Stage Small-Cell Lung Cancer: CALGB 30306, a Phase II Study. Journal of Clinical Oncology, 29, 4436-4441. http://dx.doi.org/10.1200/JCO.2011.35.6923

[31] Spigel, D.R., Townley, P.M., Waterhouse, D.M., Fang, L., Adiguzel, I., Huang, J.E., Karlin, D.A., Faoro, L., Scappaticci, F.A. and Socinski, M.A. (2011) Randomized Phase II Study of Bevacizumab in Combination with Chemotherapy in Previously Untreated Extensive-Stage Small-Cell Lung Cancer: Results from the SALUTE Trial. Journal of Clinical Oncology, 29, 2215-2222. http://dx.doi.org/10.1200/JCO.2010.29.3423

[32] Mountzios, G., Emmanouilidis, C., Vardakis, N., Kontopodis, E., Hatzidaki, D., Popis, E., et al. (2012) Paclitaxel Plus Bevacizumab in Patients with Chemoresistant Relapsed Small Cell Lung Cancer as Salvage Treatment: A Phase II Multicenter Study of the Hellenic Oncology Research Group. Lung Cancer, 77, 146-150. http://dx.doi.org/10.1016/j.lungcan.2012.02.002

[33] Arnold, A.M., Seymour, L., Smylie, M., Ding, K.Y., Ung, Y., Findlay, B., et al. (2007) Phase II Study of Vandetanib or Placebo in Small-Cell Lung Cancer Patients after Complete or Partial Response to Induction Chemotherapy with or without Radiation Therapy: National Cancer Institute of Canada Clinical Trials Group Study BR.20. Journal of Clinical Oncology, 25, 4278-4284. http://dx.doi.org/10.1200/JCO.2007.12.3083

[34] Ramalingam, S.S., Belani, C.P., Mack, P.C., Vokes, E.E., Longmate, J., Govindan, R., Koczywas, M., Ivy, S.P. and Gandara, D.R. (2010) Phase II Study of Cediranib [AZD 2171], an Inhibitor of the Vascular Endothelial Growth Factor Receptor, for Second-Line Therapy of Small Cell Lung Cancer [National Cancer Institute \#7097]. Journal of Thoracic Oncology, 5, 1279-1284. http://dx.doi.org/10.1097/JTO.0b013e3181e2fcb0

[35] Rigas, J.R., Denham, C.A., Rinaldi, D., Moore, T., Smith II, J.W., Winston, R.D. and Humphrey, R. (2003) O-107 Adjuvant Targeted Therapy in Unresectable Lung Cancer: The Results of Two Randomized Placebo-Controlled Trials of Bay 12-9566, a Matrix Metalloproteinase Inhibitor [MMPI]. Lung Cancer, 41, S34. http://dx.doi.org/10.1016/S0169-5002(03)91765-X

[36] Shepherd, F.A., Giaccone, G., Seymour, L., Debruyne, C., Bezjak, A., Hirsh, V., Smylie, M., Rubin, S., Martins, H., Lamont, A., Krzakowski, M., Sadura, A. and Zee, B. (2002) Prospective, Randomized, Double-Blind, Placebo-Controlled Trial of Marimastat after Response to First-Line Chemotherapy in Patients with Small-Cell Lung Cancer: A Trial of the National Cancer Institute of Canada-Clinical Trials Group and the European Organization for Research and Treatment of Cancer. Journal of Clinical Oncology, 20, 4434-4439. http://dx.doi.org/10.1200/JCO.2002.02.108

[37] Pujol, J.L., Breton, J.L., Gervais, R., Tanguy, M.L., Quoix, E., David, P., Janicot, H., Westeel, V., Gameroff, S., Genève, J. and Maraninchi, D. (2007) Phase III Double-Blind, Placebo-Controlled Study of Thalidomide in ExtensiveDisease Small-Cell Lung Cancer after Response to Chemotherapy: An Intergroup Study FNCLCC cleo04 IFCT 00-01. Journal of Clinical Oncology, 25, 3945-3951. http://dx.doi.org/10.1200/JCO.2007.11.8109

[38] Lee, S.M., Woll, P.J., Rudd, R., Ferry, D., O’Brien, M., Middleton, G., Spiro, S., James, L., Ali, K., Jitlal, M. and Hackshaw, A. (2009) Anti-Angiogenic Therapy Using Thalidomide Combined with Chemotherapy in Small Cell Lung Cancer: A Randomized, Double-Blind, Placebo-Controlled Trial. Journal of the National Cancer Institute, 101, 10491057. http://dx.doi.org/10.1093/jnci/djp200

[39] Sharma, N., Pennell, N., Nickolich, M., Halmos, B., Ma, P., Mekhail, T., Fu, P. and Dowlati, A. (2014) Phase II Trial of Sorafenib in Conjunction with Chemotherapy and as Maintenance Therapy in Extensive-Stage Small Cell Lung Cancer. Investigational New Drugs, 32, 362-368. http://dx.doi.org/10.1007/s10637-013-0061-6

[40] Ready, N.E., Pang, H.H., Gu, L., Otterson, G.A., Thomas, S.P., Miller, A.A., et al. (2013) Chemotherapy with or without Maintenance Sunitinib for Untreated Extensive-Stage Small Cell Lung Cancer: A Randomized, Placebo Controlled Phase II Study CALGB 30504 [ALLIANCE]. Journal of Clinical Oncology, 31, 7506.

[41] Heist, R.S., Fain, J., Chinnasami, B., Khan, W., Molina, J., Brainerd, V., Leopold, L. and Lynch, T. (2009) A Phase I/II [P1/P2] Study of AT-101 in Combination with Topotecan[t] in Patients with Relapsed or Refractory Small Cell Lung Cancer [SCLC] after Prior Platinum-Containing First-Line Chemotherapy. Journal of Clinical Oncology, 27, 8106.

[42] Lara Jr., P.N., Chansky, K., Davies, A.M., Franklin, W.A., Gumerlock, P.H., Guaglianone, P.P., Atkins, J.N., Farneth, N., Mack, P.C., Crowley, J.J. and Gandara, D.R. (2006) Bortezomib [PS-341] in Relapsed or Refractory Extensive Stage Small Cell Lung Cancer: A Southwest Oncology Group Phase II Trial [S0327]. Journal of Thoracic Oncology, 1, 996-1001. http://dx.doi.org/10.1097/01243894-200611000-00013

[43] Gandhi, L., Chu, Q.S., Stephenson, J., Johnson, B.E., Govindan, R., Bonomi, P., Eaton, K., Fritsch, H., Munzert, G. and Socinski, M. (2009) An Open Label Phase II Trial of the Plk1 Inhibitor Bi 2536, in Patients with Sensitive Relapse Small Cell Lung Cancer [SCLC]. Journal of Clinical Oncology, 27, 8108.

[44] Prystowsky, M., Feeney, K., Kawachi, N., Montagna, C., Willmott, M., Wasson, C., Antkowiak, M., Loudig, O. and Parish, J. (2013) Inhibition of Plk1 and Cyclin B1 Expression Results in Panobinostat-Induced $\mathrm{G}_{2}$ Delay and Mitotic Defects. Scientific Reports, 3, 2640. http://dx.doi.org/10.1038/srep02640

[45] Crisanti, M.C., Wallace, A.F., Kapoor, V., Vandermeers, F., Dowling, M.L., Pereira, L.P., et al. (2009) The HDAC In- 
hibitor Panobinostat [LBH589] Inhibits Mesothelioma and Lung Cancer Cells in Vitro and in Vivo with Particular Efficacy for Small Cell Lung Cancer. Molecular Cancer Therapeutics, 8, 2221-2231. http://dx.doi.org/10.1158/1535-7163.MCT-09-0138

[46] Minami, T., Kijima, T., Kohmo, S., Arase, H., Otani, Y., Nagatomo, I., et al. (2013) Overcoming Chemoresistance of Small-Cell Lung Cancer through Stepwise HER2-Targeted Antibody-Dependent Cell-Mediated Cytotoxicity and VEGF-Targeted Antiangiogenesis. Scientific Reports, 3, 2669. http://dx.doi.org/10.1038/srep02669

[47] Abidin, A.Z., Garassino, M.C., Califano, R., Harle, A. and Blackhall, F. (2010) Targeted Therapies in Small Cell Lung Cancer: A Review. Therapeutic Advances in Medical Oncology, 2, 25-37. http://dx.doi.org/10.1177/1758834009356014

[48] Giaccone, G., Debruyne, C., Felip, E., Chapman, P.B., Grant, S.C., Millward, M., Thiberville, L., D’addario, G., Coens, C., Rome, L.S., Zatloukal, P., Masso, O. and Legrand, C. (2005) Phase III Study of Adjuvant Vaccination with Bec2/Bacille Calmette-Guerin in Responding Patients with Limited-Disease Small-Cell Lung Cancer (European Organisation for Research and Treatment of Cancer 08971-08971B; Silva Study). Journal of Clinical Oncology, 23, 6854-6864. http://dx.doi.org/10.1200/JCO.2005.17.186

[49] Antonia, S.J., Mirza, N., Fricke, I., Chiappori, A., Thompson, P., Williams, N., Bepler, G., Simon, G., Janssen, W., Lee, J.H., Menander, K., Chada, S. and Gabrilovich, D.I. (2006) Combination of p53 Cancer Vaccine with Chemotherapy in Patients with Extensive Stage Small Cell Lung Cancer. Clinical Cancer Research, 12, 878-887.

[50] Kola, I. and Landis, K. (2004) Can the Pharmaceutical Industry Reduce Attrition Rates? Nature Reviews Drug Discovery, 3, 711-715.

[51] Carden, C.P., Sarker, D., Postel-Vinay, S., Yap, T.A., Attard, G., Banerji, U., et al. (2010) Can Molecular BiomarkerBased Patient Selection in Phase I Trials Accelerate Anticancer Drug Development? Drug Discovery Today, 15, 88-97. http://dx.doi.org/10.1016/j.drudis.2009.11.006

[52] Stratmann, A.T., Fecher, D., Wangorsch, G., Göttlich, C., Walles, T., Walles, H., Dandekar, T., Dandekar, G. and Nietzer, S.L. (2013) Establishment of a Human 3D Lung Cancer Model Based on a Biological Tissue Matrix Combined with a Boolean in Silico Model. Molecular Oncology, 8, 351-365.

http://dx.doi.org/10.1016/j.molonc.2013.11.009 
Scientific Research Publishing (SCIRP) is one of the largest Open Access journal publishers. It is currently publishing more than 200 open access, online, peer-reviewed journals covering a wide range of academic disciplines. SCIRP serves the worldwide academic communities and contributes to the progress and application of science with its publication.

Other selected journals from SCIRP are listed as below. Submit your manuscript to us via either submit@scirp.org or Online Submission Portal.
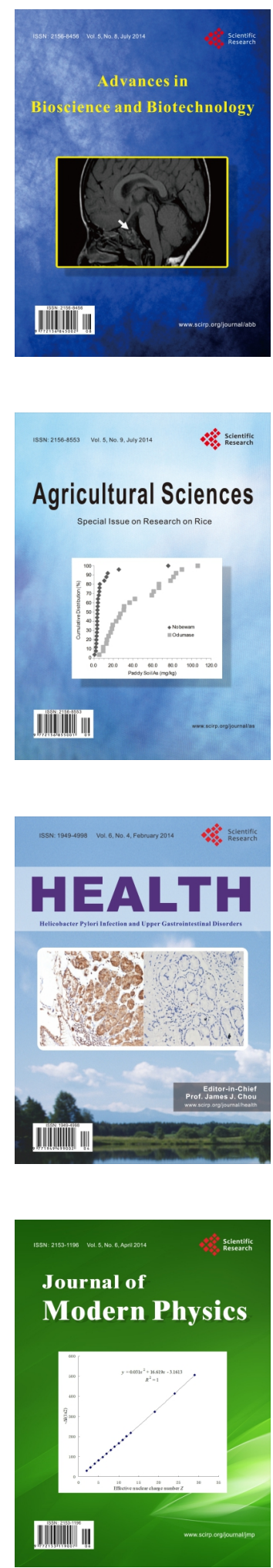
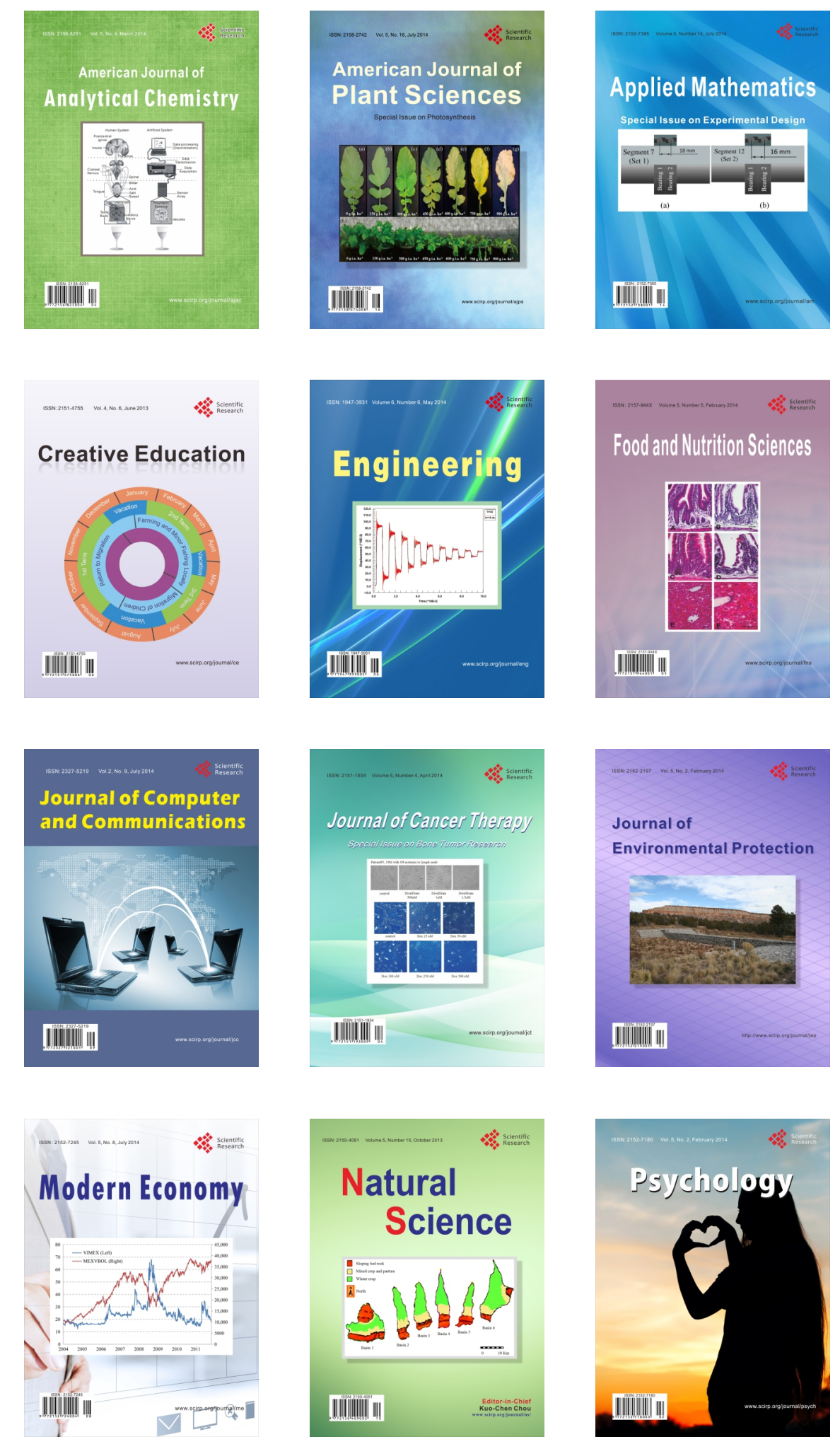